\title{
The semantics and morphology of household container names in Icelandic and Dutch ${ }^{\text {is }}$
}

\author{
Matthew Whelpton ${ }^{\mathrm{a}, *}$, pórhalla Guðmundsdóttir Beck ${ }^{\mathrm{a}}$, Fiona M. Jordan ${ }^{\mathrm{b}, \mathrm{c}}$ \\ a School of Humanities, University of Iceland, Sæmundargötu 2, 101 Reykjavík, Iceland \\ ${ }^{\mathrm{b}}$ Department of Archaeology \&' Anthropology, University of Bristol, 43 Woodland Rd, Bristol BS8 1UU, United Kingdom \\ ${ }^{\mathrm{c}}$ Evolutionary Processes in Language and Culture, Max Planck Institute for Psycholinguistics, The Netherlands
}

\section{A R T I C L E I N F O}

\section{Article history:}

Available online 1 September 2014

\section{Keywords:}

Naming strategies

Object classification

Extensions

Intensions

Compounding

Diminutives

\begin{abstract}
A B S T R A C T
In this paper, we report an experiment on the naming of household containers in Dutch and Icelandic carried out as part of the Evolution of Semantic Systems project (EoSS; Majid et al., 2011). This naming experiment allows us to support and elaborate on a hypothesis by Malt et al. (2003) that productive morphology in the naming domain can have an influence on boundary placement within the extensional space. Specifically, we demonstrate that the Dutch diminutive - $(t) j e$ favours a cut between small items versus others, whereas Icelandic, which does not use the diminutive in this domain, favours a cut between large items and others. This is not a typological effect, as Dutch and Icelandic are both Germanic languages and both have diminutive morphology available in principle. We find no evidence that the diminutive produces a proliferation of terms and/or fine-grained nesting within the extensional domain. Rather, the Dutch diminutive favours a more even distribution of terms across the space whereas Icelandic favours broad inclusive terms with a number of narrower specialist terms. Further, the extensional space defined by the diminutive is not associated with its own clear prototypical exemplar. Using evidence from compounding and modification, we also consider which semantic features are prominent in differentiating categories within the domain. By far the most prominent in both languages is the inferred contents of the container. Other than contents, however, the languages differ in the range and prominence of features such as intended usage or material of composition. Our results demonstrate that in order to understand the processes that produce semantic divisions of basic object classes, we should consider fine-grained analyses of closely related languages alongside analyses of typologically different languages.
\end{abstract}

(c) 2014 Elsevier Ltd. All rights reserved.

\section{Introduction}

"Many a slip twixt cup and lip" runs the proverb, and the act of drinking from a container suitable for the purpose seems so natural that we rarely question how we know what a cup is. The question seems especially strange when considering historically and culturally related languages: surely English cup, Dutch kopje and Icelandic bolli mean essentially the same thing?

\footnotetext{
is This work stems from the Evolution of Semantic Systems project and received financial support from the Max Planck Gesellschaft. For consultation on Dutch word usage, FMJ would like to thank Christiaan Oostdijk and MW would like to thank Désirée L. Neijmann. The authors thank the two anonymous reviewers for their constructive suggestions on revising this paper. All remaining errors and confusions are ours solely.

* Corresponding author. Tel.: +354 525 4451(off); +354 864 4534(mob); fax: +354 5254410.

E-mail addresses: whelpton@hi.is (M. Whelpton), tgb@hi.is (b. Guðmundsdóttir Beck), fiona.jordan@bristol.ac.uk (F.M. Jordan).
} 
The question of how naming practices relate to concepts on the one hand and the natural organisation of the world on the other is an enduring topic of controversy and debate in a number of fields, including philosophy, psychology, linguistics and anthropology. It has been claimed that in some cases the world is structured in such a way as to cry out to our senses to be named (Berlin, 1992; Hunn, 1977; cited by Malt et al., 2003). Objects, particularly those with boundaries and functions readily discernible from other aspects of our surroundings, could be thought of as exemplifying such external structural categories. Others have claimed that this apparent structure is in fact made by our own senses, and that our minds are innately endowed with instinctive frames of reference that organise the input of our senses in characteristic ways (Fodor, 1975). As Chomsky puts it: "But no one can seriously doubt that for all organisms, what counts as experience is richly determined by internal factors, which construct an organism-specific Umwelt” (Chomsky, 2003, p. 301). Others have repudiated the idea that either the world or our minds provide any inherent structure at all. Rather it is the systematic pattern of our own language, its vocabulary and grammatical organisation, which imposes a structure upon our perceptions where no such structure exists (Sapir, 1929, 1912; Whorf, 1956). Or again, it may be that language only has the influence it does because it is culturallytransmitted, and it is really cultural practices in all their forms that are decisive in categorisation: as Malt and Majid (2013, p. 590) put it, "could perception and cognition be culture-dependent all the way down"?

In this paper, we follow up on a series of psycholinguistic experiments concerning the naming of household containers as a class within the domain of objects, and we report our own experiment on the naming of household containers in Dutch and Icelandic carried out as part of the Evolution of Semantic Systems project (EoSS; Majid et al., 2011). We argue in favour of a hypothesis by Malt and her colleagues (Malt et al., 2003, p. 35; Malt and Majid, 2013, p. 588) that the morphology of a language can have an influence on the placement of extensional boundaries within a lexical domain. Specifically, we argue that the diminutive suffix -(t)je in Dutch encourages a separation of small from other objects in the lexicalisation of the container domain. This is not observed in Icelandic, where the break is more typically between small and medium objects on the one hand and large ones on the other. This is a significant extension and refinement of Malt et al.'s observation, as our anlaysis is based on two typologically closely related languages and involves a detailed analysis of a morphological process that Malt and her colleagues do not consider: diminutive formation. We also consider evidence from compounding and modification in the two languages to identify other features of meaning that are used for object differentiation in container naming and consider in a preliminary fashion the degree to which these represent variable cultural constructions.

We address the following questions in this paper. Can differences in morphological strategy influence the way that an extensional domain is carved up? If so, do the differences relate to broad typologically-based differences or narrower differences in the productivity of particular morphemes? We then consider what kinds of differences are produced. For instance, are there differences in extensional boundary placement, and/or proliferation of terms within the domain? If our results suggest that a morpheme does influence boundary placement in the extensional domain, can we also see the morpheme attracting a strong prototypical exemplar within that extensional space, as revealed in high inter-speaker agreement in naming? Finally, what features of meaning are important for differentiation within the domain, and to what extent are they variable?

To provide context for these questions we review the background literature on container naming (Section 2.1) and our assumptions concerning diminutive formation and compounding (2.2). In Section 3, we describe the data collection and coding methodology used by the EoSS project data and results that we report here, as well as some of the methodological issues that emerged with respect to our data. In Section 4, we present our findings and in Section 5 our conclusions.

\section{Background}

\subsection{Literature on containers}

\subsubsection{General background}

Naming practices can vary considerably between languages, even in the naming of familiar physical objects such as household containers. Kronenfeld et al. (1985) investigated the naming of 11 drinking vessels (such as cups, mugs and glasses) by Japanese, American English, and Israeli Hebrew speakers. They found that the extensional range of names in the languages varied considerably, guided by different prototypical exemplars and salient attributes. Hebrew speakers distinguished between two broad categories, separating tea and coffee cups from other kinds of drinking vessels. English speakers also made a two-way distinction but separated glass drinking vessels off from the others (e.g. cups). Japanese speakers made a three-way distinction, using a special category for wine glasses. Malt et al. (2003) found similar crosslinguistic diversity and no "compelling structure ... in the world" (p. 21) in their study of the naming of household containers such as bottles, jars and cans by speakers of (Argentinian) Spanish, (American) English and (Mandarin) Chinese. Ameel et al. (2005) replicate the findings of Malt and her colleagues for Belgian speakers of Dutch and French, showing not only that monolingual speakers have distinct naming practices, despite their largely shared cultural environment, but also that Dutch-French bilinguals develop their own partially merged classification system distinct from the systems of monolinguals.

Collectively, these findings might be seen as providing support for a strong version of the linguistic relativity hypothesis (cf. Boroditsky, 2006; Lucy, 1992), i.e. that arbitrary linguistic categories condition thought and conceptualisation. Malt et al. (1999) challenged this position in their study of Spanish, English and Chinese naming practices. Here they also collected non- 
linguistic similarity judgements, where participants sorted the picture stimuli into piles on the basis of (a) overall similarity (no conditioning context), (b) physical similarity only, and (c) functional similarity only. Although they found that naming practices diverged between the three languages, the non-linguistic similarity judgements were extremely similar (p. 245): there was only a negligible difference in overall similarity, and only small differences in physical and functional similarity (though still significantly higher in similarity than for naming conventions).

Even in their 2003 study, where they establish clear differences in naming practices, Malt et al. (2003) argue strongly against a radical cross-cutting of categories which would imply that there is "a large degree of independence of linguistic categories from any shared understanding of the domain... [implying] either that sufficient perceived structure in the world does not exist to compel shared naming patterns, or that such structure exists (and may underlie non-linguistic groupings) but the processes that produce linguistic diversity overwhelm the influence of such structure in naming patterns" (p. 22). Rather, they argue that there are sufficient signs of extensional correspondence and nesting in their naming data that a mixed approach is necessary, i.e. that their naming data reflect the interplay of individual conceptualisations, cultural and linguistic naming practices, and structure within the domain itself.

In their discussion of linguistic factors (p. 35), they take a position that we argue in favour of here, namely that productive morphemes in a naming domain can influence the assignment of extensional boundaries. They give the example of the productive Spanish instrumental suffixes -ero/-era/-or which describe objects used for performing a particular action, e.g. mamadera naming an object for sucking on. They suggest that the availability of these morphemes for container naming might explain the proliferation of names within their Spanish data, as opposed to the English and Chinese data. We establish that this effect is not a broad typological one but rather related to the specific morphology which is productive in a particular naming domain. We compare Icelandic and Dutch, two closely related languages, which differ in their use of diminutive morphology and show that the Dutch diminutive suffix - $(t) j e$ has a significant effect on the placement of extensional boundaries. However, unlike Malt and her colleagues, we see no evidence for profileration in naming.

Another influential tradition in the analysis of categories established by naming is prototype theory (Rosch, 1973, 1975). Labov (1973) used container naming in a set of experimental approaches to the study of words and meanings. In these experiments, American English speakers were asked to name outline drawings of cups, bowls and vases that varied along certain dimensions; various imagined features of the contexts were altered as well, such as the materials the objects were made of and their potential contents. Results demonstrated that speakers named these items variably but with consistent patterns that were evoked by different imagined settings or features. For example, imagining 'coffee' as a context led speakers to name an item as 'mug' more so than in a neutral context; imagining 'flowers' for the same item led to speakers using the name 'vase' (Labov, 1973, p. 51). Extending this, Rosch's approach led to her formulation of prototype theory, where a prototype is a central member of a category and other members are more-or-less like their prototype. These theoretical perspectives are useful for the interpretation of patterns of inter-speaker agreement in our data as well as the analysis of semantic features in compounding in Sections 4.3 and 4.4.

\subsubsection{Dutch containers}

The stimulus materials used in these investigations and as part of the EoSS project are the "dishes set" described in Ameel et al. (2005, p. 64). In that work, Ameel and her colleagues compare the naming practices of three linguistic groups in Belgium: Dutch monolinguals, French monolinguals and Dutch-French compound bilinguals, i.e. those who were exposed systematically from birth to two languages and so grew up with two native languages (Ameel et al., 2005, p. 78). In addition to the dishes set of stimuli, they also used a "bottles set" similar to that reported on in Malt et al. (1999). Their aim was to test hypotheses concerning the naming practices of bilinguals (Ameel et al., 2005, p. 62): broadly, do bilinguals command two separate linguistic systems for naming which are essentially the same as for monolinguals (the two-pattern hypothesis) or do bilinguals have a single linguistic system for naming which accommodates the categories of the two languages (the onepattern hypothesis)? Their experimental design allowed them to test the findings of Malt and colleagues that divergent naming practices do not necessarily imply divergent non-linguistic similarity judgements, and to do so in a context where culture is largely shared, so that differences in naming practices must be a result of divergent linguistic conventions reflecting the distinct histories of the languages.

Using the dishes and bottles stimuli, they collected naming data and non-linguistic similarity judgements. Their analysis confirms that the monolingual naming practices of Belgian French speakers are markedly divergent from the naming practices of Belgian Dutch speakers, whereas their non-linguistic similarity judgements are extremely similar (Ameel et al., 2005, p. 70), thus replicating the findings of Malt et al. (1999). Their analysis disproves the two-pattern hypothesis: the naming practices of Dutch-French bilinguals differ from the naming practices of monolingual Dutch and French speakers from the same cultural environment. However, their analysis also disproves a strong version of the one-pattern hypothesis, which claims that bilinguals have a single set of naming conventions and the two languages simply provide different labels for those naming categories. Rather, the bilinguals showed slightly different naming practices in their two languages. Ameel and her colleagues therefore argue in favour of a weak version of the one-pattern hypothesis, in which bilinguals accommodate towards a single system, with each language pulled slightly towards the naming patterns of monolingual speakers: "The moderate hypothesis allows the portions of stimulus space associated with a word in one language and its translation equivalent in the other language to be more shared than they are in monolinguals, but not perfectly identical" (Ameel et al., 2005, p. 77). 


\subsubsection{Icelandic containers}

Little research has been conducted on container names in Icelandic, though the Department of Lexicography at the Árni Magnússon Institute for Icelandic Studies does have lists of container names and associated information (including etymology and translation information in some cases). Only one major study has been conducted on the semantics of Icelandic container terms: Höskuldur práinsson's (1979) replication for Icelandic of Labov's (1973) study. práinsson took the 19 line drawings of containers used by Labov and supplemented them with 9 additional drawings, created by removing the handle from a subset of the original drawings, giving a total of 28 drawings.

There were 68 participants in the study (bráinsson, 1979, p. 99). Some participants were presented the stimuli individually and asked to name the container orally; their responses were recorded and then transcribed. Others were presented with the stimuli in small groups and asked to write the corresponding term on a handout provided. Participants were also divided into subgroups according to contextual biasing: 31 participants were simply told that they would see a kitchen container (Ic. eldhúsílát); 16 participants were asked to imagine that they had arrived for a visit and their host was pouring coffee into the container; 10 participants were asked to imagine that they walked into the kitchen and saw the relevant container on the table, full of mashed potatoes; finally, 11 participants were asked to imagine that they saw the container on a shelf or table with flowers in it.

In the summary of main responses from the 31 neutral-context participants (práinsson, 1979, p. 101, his Table 2), 6 terms occur as the most often given response: bolli (a cup), kanna (a tall drink container such as a mug, tankard or jug), staup (a shot glass), skál (a bowl), glas (a drinking glass) and dolla (a pot). Of these, only bolli, staup, skál, and glas are given as majority responses to at least one drawing and only bolli is ever given as the sole response to a drawing (in fact, twice). The word bolli has a strong prototypical core (práinsson, 1979, p. 106): a height:width ratio of 1:1.6, tapering convex sides and handle. Deviations from this core triggered modification (e.g. lágur víður bolli 'low wide cup') and compounding (e.g. tebolli 'teacup').

With respect to contextual biasing, práinsson (1979, p. 104) discovered that in some cases container contents had a strong effect on classification but in others almost no effect at all: essentially prototypical items resisted biasing where intermediate items were strongly affected. For instance, items which resemble cups without handles (\#20-22) were only named as bolli in a very few cases in the neutral group. However, bolli was the majority response in the group asked to image the container with coffee in. On the other hand, the prototypical bolli (\#1) was called bolli by all participants in all groups, regardless of coffee, mashed potato or flower contents.

This study therefore demonstrates standard prototypicality effects with exemplar items receiving high inter-speaker agreement in naming. The form of the container appears to have a decisive effect on receiving the name bolli but in doubtful cases the contents of the container has a significant effect also. In Section 4.3, our naming data shows the same prototypical focus for bolli as in práinsson's study and in Section 4.4, our analysis of compounding patterns confirms container contents as the most salient additional classificatory factor in both languages. However, other factors appear in our data than are reported in the práinsson study and our languages differ in the prominence of those additional factors.

\subsection{Word formation, Dutch and Icelandic}

In this article, we consider evidence relating to two word formation processes with respect to categorisation in the container domain in Dutch and Icelandic. Our primary claim concerns the influence of diminutive morphology in Dutch on the extensional boundaries in the container domain in contrast to Icelandic, where diminutive morphology is not used. ${ }^{1}$ We follow Jurafsky ${ }^{2}$ (1996) in understanding the dimunitive broadly to be "any morphological device which means at least 'small"' (534). Crosslinguistically the diminutive can be realised by a range of morphological devices and expresses a radial category with a number of characteristic sense extensions. However, in this paper, we refer by the term diminutive primarily to the morpheme - $(t) j e$ in Dutch, the sole diminutive morpheme to occur in container names in our data. It is primarily used with the core sense of relative smallness or "smallness in kind" as Shetter (1959, p. 79) puts it in his analysis of the Dutch diminutive, though in our discussion of prototypicality we see possible evidence of its attitudinal use (Shetter and Ham, 2007).

It is not surprising that the diminutive - $(t) j e$ emerges so prominently in our data given that Dutch has been noted for its "fondness for the diminutive" (Brachin, 1985, p. 63). The Standard Dutch diminutive nominal suffix comes in a small number of phonological allomorphs of -tje (Shetter, 1959; van der Hulst, 2008; Booij and van Santen, 1998), and all nouns as well as some adjectives, verbs, and adverbs are liable to be used in a diminutive form (Cohen, 1958; Shetter, 1959). Semantically, diminutives do not necessarily express small size, although that is their basic function (Jurafsky, 1996). In some cases they introduce an individuating sense which shifts the denotation of the word e.g. brood 'bread' > broodje 'bread roll', scheermes 'razor' > scheemertje 'razor blade' (Shetter and Ham, 2007; Shetter, 1959). Of particular relevance here, diminutives may act to itemize mass nouns, particularly food and drink, e.g. bier 'beer' > een bier(tje) 'a glass of beer', drop 'licorice' > een drop(je) 'a piece of licorice' (Donaldson, 2003; Shetter, 1959). Further, diminutives may be used to convey endearment, to soften, or express something modestly, but may also be used to convey contempt or disrespect (Brachin, 1985), i.e. evaluative attitudes of the speaker to the item named or a personal response to it (Shetter and Ham, 2007).

\footnotetext{
${ }^{1}$ However, see Section 4.4 for our discussion of compounded adjectives expressing small size such as ör- 'tiny'.

${ }^{2}$ We thank a reviewer of this paper for directing us to this useful reference.
} 
Diminutives do exist in Icelandic, though there is very little scholarly literature concerning them. Guðrún Kvaran (2005, p. 138) observes that the suffix -lingur is used to derive diminutives, e.g. grís 'pig' + lingur 'DIM' gives gríslingur 'piglet' and strák 'boy' + lingur 'DIM' gives stráklingur '(young) lad'. This suffix has been used to support the drive for pure lexical stock, for example in naming new technologies: disk 'disc' + lingur 'DIM' gives disklingur 'diskette'. Jóhannesson (1927) describes this suffix as very productive at that time but Kvaran observes that though it is still available it is no longer as productive. Another diminutive that occurs in child language is tásla (sometimes tása) 'toesie' which is a diminutive of tá 'toe'. In contemporary Icelandic, neither diminutive is particularly productive and no diminutives at all were used as container names in the Icelandic data reported here.

We also include a discussion of compounding patterns in the Icelandic and Dutch data. By compound we refer to the combination of two or more nouns into a single nominal constituent (e.g. English coffee cup, Icelandic kaffibolli, Dutch koffiekopje). Both Icelandic and Dutch form right-headed compounds, so that kaffibolli is a kind of bolli and shares the distributional and inflectional properties of bolli; similarly for koffiekopje and kopje. Whether or not the compound is written as one or two words is not relevant to it being treated as a compound in our analysis. We also include adjectival compounds in Icelandic where the adjective is compounded in its root form rather than taking the agreement morphology required for attributive uses (e.g. djúpdiskur vs djúpur diskur). Some of these may be seen as taking a diminutive semantics (e.g. ör- 'tiny') and we discuss this in Section 4.4.

Icelandic has a highly productive system of compounding, which was clearly reflected in our data, as compounding is the primary strategy used by Icelandic participants to elaborate their container descriptions. This is in part driven by the strong purist tradition which supports a preference for native-stock alternatives to foreign word loans. New terminology is often created by compounding rather than borrowing. A typical example is umhverfis + mála + rádu + neyti (lit. environment + matters + control + group) 'ministry of the environment'. Guðrún Kvaran (2005, p. 151) reports that in a survey of a corpus of 610,500 words, $85 \%$ involved compounding (Jónsson, 1988, p. 5). Vikør (2001, p. 216) comments that "[t] here is little doubt that the Icelandic nýyrðastefna ('new-word-ism') has a solid majority of the population behind it". It is certainly a robust word-formation strategy in our data.

Dutch shares with Icelandic and other Germanic languages the capacity for arbitrarily long compounds, leading to an extensive vocabulary and the largest dictionary in the world (the Woordenboek der Nederlandsche Taal). The most frequent kind of Dutch compound is when multiple nouns are joined together, with the last noun as the head element (Shetter and Ham, 2007). Nouns can also be compounded with verb stems, adjectives, adverbs, and prepositions, and non-noun compounds can be formed as well. Compounding was also a prominent feature of the Dutch EoSS data but, as we will see, was considerably less elaborate than in Icelandic.

\section{Evolution of Semantic Systems project and methodology}

The data reported in this paper was originally collected as one part of the EoSS project (Majid et al., 2011), using a standardised elicitation task.

\subsection{The elicitation task}

In the EoSS container naming task, participants were asked by the native-speaker experimenter to name 67 different household containers: these stimuli were the "dishes set" from Ameel et al. (2005), available from the lead author's website ${ }^{3}$ and used with permission as part of the EoSS project. Pictures were presented in a colour booklet where each container had been photographed from a constant distance to preserve size information, and a ruler was included in the photograph for reference. Participants were instructed that they would be shown a series of common household containers and asked to give a simple description: the first name that came to mind. The prompt question "What do you call this?" was used occasionally throughout the session. Each session was audio recorded and later transcribed by the experimenter.

\subsection{Participants}

The EoSS protocol required a minimum of 20 participants. The Netherlands Dutch native-speaker participants $(n=21,16$ women) were currently all students at the Radboud University, Nijmegen, and aged between the ages of 19-27 years ( mean $=21.5$ ). The Icelandic native-speaker participants $(n=21,10$ women) were aged $19-57$ years $($ mean $=29) .14$ were either currently university students or had completed higher education, though 4 had completed only compulsory primary schooling. ${ }^{4}$

\footnotetext{
3 http://fac.ppw.kuleuven.be/lep/concat/eef/index.php?stimuli.

${ }^{4}$ As the reviewers pointed out, this mixed education background may be potentially problematic for comparing naming practices. The conclusions of this paper are based primarily on dominant responses to the stimuli to minimise the effect of this factor. High proficiency in English is common in both Iceland and The Netherlands, especially amongst the university educated; our participants were not unusual in this respect. Given Ameel et al. (2005) study of bilingual naming categories, this raises important questions concerning the structure of contemporary Icelandic and Dutch naming categories versus those of a century ago. It is nevertheless part of the current sociolinguistic reality of Northern European nations that English proficiency is high.
} 


\subsection{Data coding}

The complete response given by each participant to each stimulus was transcribed into a standardised spreadsheet as the full response. That full response was then associated with the transparent morphological and semantic head of the noun used to name the stimulus as the main response. For instance, if a participant responded "it's a black coffee cup" (full response), then cup was coded as the main response because cup is the morphological head of the compound coffee cup and the semantic relation between the compound and the morphological head is transparent: a coffee cup is a kind of cup (hyponym relation). Where a participant gave more than one possible response, each noun was coded as a main response. For instance, the full response "it's a cup, a mug", would be coded for two main responses cup and mug.

In some cases, the choice of a coded main response was problematic, usually because the relationship between the nominal in the full response and the morphological head noun was not (entirely) semantically transparent. For instance, the compound noun ashtray is made up morphologically of two nouns ash + tray. However, most speakers do not accept that an ashtray is a kind of tray and ashtrays can take a form which is quite different from the form of trays. In this case, the whole nominal term "ashtray" is coded as the main response. In Icelandic, examples of this are: kertastjaki (lit. candle + stake) 'candlestick', sykurkar (lit. sugar + tub) 'sugar bowl', undirskál (lit. under + bowl) 'saucer' and öskubakki (lit. ash + tray) 'ashtray'. In Dutch, examples are: asbak 'ashtray', dienblad 'tray', eierdopje and eierdop 'eggcup'.

In some cases, the transparency issue is not quite so straightforward. In Icelandic, the term kertastandur (lit. candle + stand) 'candle stand' is coded as standur because the compound is semantically transparent, i.e. a kertastandur is a kind of standur. The term kertahaldari (lit. candle + holder) 'candle holder' is formally and semantically analogous with kertastandur in the sense that a kertahaldari is a kind of haldari. The problem is that haldari does not naturally occur on its own as a free lexeme: here it appears to be a nonce formation, possibly influenced by the English term candle holder. The whole compound has therefore been coded as a main response. Similar terms occurred in Dutch but there it was judged that both terms were dependent, like the -haldari example in Icelandic. Both waxinelichthouder (lit. wax + light + holder) 'tealight candleholder' and kaarsenstandaard (lit. candle + stand) 'candleholder' were coded as main responses. Standaard was not judged to occur freely in this sense, as it requires further elaboration by compounding to be acceptable, as in fietsenstandaard 'bicycle stand' or muziekstandaard 'music stand'.

Where the full response did not contain a container name, then the main response was coded as an error. Nonresponses were therefore coded as errors, as were responses like hettan in Icelandic, the word for a contraceptive diaphragm given in response to a picture of a small pink bowl; hettan was coded as an error on the basis that the object in the picture was perceived as something other than a container. As long as a container reference could be established, the term was coded. For instance, the term fingurbjörg (lit. finger + protection) 'thimble' in Icelandic was originally coded as an error on the grounds that it does not refer to a container term. However, further research revealed that this term is in fact used for a drink container, especially a very small cup for strong espresso coffee ${ }^{5}$ : fingurbjörg was therefore coded as a main response.

One other important coding point needs to be mentioned. In the parent EoSS project, diminutives were coded as main responses separately from their root terms to allow for the possibility of lexicalisation effects in the use of diminutive terms. This paper argues that the productivity of diminutives in the Dutch naming data encourages the placement of extensional boundaries in a different place from Icelandic, which does not use the diminutive at all in container naming. In Ameel et al. (2005) diminutives were collapsed with their root forms on the basis that adjectival modification relating to size was also ignored. In Section 4.1, we therefore provide both versions of our data (with and without diminutives) for the comparison with Ameel et al. (2005). The issue of compounding versus modification in the expression of size is taken up in Section 4.4.

In this paper, we refer to coded main responses as head terms because they are the smallest semantically transparent term containing the morphological head (but may, as in the case of ashtray, be morphologically complex). We refer to the nominal portion of the full response (e.g. coffee cup) as a nominal term. So, the nominal term coffee cup would be coded as the head term cup. In this paper we make special reference to high-frequency head terms, by which we refer to those head terms which are used at least 20 times (overall token frequency for all stimuli and all participants) and by over half of the participants (i.e. over half the participants used the term for at least one stimulus). These high-frequency head terms represent the salient lexical divisions in the semantic extensional space.

\section{Results}

\subsection{General overview}

The stimuli elicited 36 head terms in Icelandic, shown in (1), and 35 head terms in Dutch, shown in (2) (excluding the error category). The terms are ordered by token frequency (in brackets) and the bold items are high-frequency head terms in the sense defined in Section 3.3 (11 for Icelandic; 12 for Dutch).

${ }^{5}$ http://parisardaman.free.fr/?s=ordalisti. 
(1) skál (509); bolli (287); diskur (166); fat (97); glas (69); kanna (59); mót (56); krús (31); öskubakki (30); mál (29); undirskál (25); ílát (25); bakki (24); krukka (11); kertastjaki (7); dallur (6); panna (6); fantur (5); sykurkar (4); form (3); dolla (2); munur (2); prammi (2); áhald (2); box (1); coaster (1); fingurbjörg (1); hirsla (1); ker (1); kertahaldari (1); koppur (1); mortél (1); pottur (1); standur (1); staup (1); vasi (1)

(2) schaal (277); schaaltje (194); bord (132); kopje (122); bakje (119); mok (111); kom (68); beker (66); glas (59); kommetje (56); bordje (35); kop (30); pul (28); bak (18); glaasje (15); potje (14); schoteltje (11); bekertje (10); schotel (7); asbak (6); dienblad (6); mokje (4); pannetje (4); pot (4); doosje (2); eierdopje (2); kroes (2); plaat (2); blad (1); eierdop (1); kaarsenstandaard (1); kalebas (1); standaard (1); vaas (1); waxinelichthouder (1)

The Dutch list includes 12 diminutives, 10 of which occur along with their root term, as shown in (3).

(3) schaal-schaaltje; bord-bordje; kop-kopje; bak-bakje; kom-kommetje; beker-bekertje; glas-glaasje; pot-potje; schotel-schoteltje; eierdop-eierdopje; pannetje; doosje

Only pannetje and doosje occur exclusively in diminutive form. Amongst the high-frequency terms (again marked in bold), there are 5 diminutives, including three pairs (schaal $\sim$ schaaltje; kom $\sim$ kommetje; bord $\sim$ bordje). Among the Icelandic head terms, no diminutives occur at all (but see our discussion in Section 4.4 on compounded adjectives).

Following Malt et al. (2003), Ameel et al. (2005) report the dominant terms for their stimuli, including the Dutch responses to the 67 dishes stimuli, where dominant terms refers to the term given most often for a particular stimulus. Table 1 shows a list of the dominant terms reported for Belgian Dutch in Ameel et al. (2005, p. 68, from their Table 2), as well as the dominant terms from our participants, first with diminutive and non-dimunitive terms collapsed and then noncollapsed; for the sake of completeness we also show the list of Icelandic dominant terms. Note that, where there was a tie for most frequent response, we included both terms for the object (see Table 2 for full details), whereas Ameel and colleagues appear to have had a unique dominant term for every item. In brackets is the number of stimuli that received that term as the dominant term.

An immediate conclusion with respect to our research questions is that the use of the diminutive in Netherlands Dutch is not producing a proliferation in naming terms of the kind that Malt et al. (2003) describe for Spanish. Indeed Icelandic has more dominant terms than Dutch, even with diminutives counted. The question of whether the diminutive suffix affects extensional boundary placement - and in particular, the kind of fine-grained nesting that Malt and her colleagues observe for the instrumental suffix in Spanish - will be addressed in the next section.

A comparison of the results in Ameel et al. (2005) for Belgian monolingual speakers of Dutch (Leuven University, Belgium) and the EoSS results for Netherlands speakers of Dutch (Radboud University, Nijmegen, the Netherlands) shows some striking dialect differences. In the Ameel results, kom is the dominant bowl term, with schaal(tje) coming in third place. In the EoSS data schaal(tje) is by far the most frequent dominant name with kom towards the bottom of the list. In the Ameel results, tas emerges as the clearly salient term in the cup domain, with the two other drinking vessels (beker and glas) serving distinct functions (see more detailed discussion in Section 4.2). However, in the EoSS data, drinking vessels are more evenly distributed across a broader number of names with kop(je) and mok and pul sharing the space along with glas and beker. The dialect term tas does not appear at all. Similarly, the dominant drinking vessel term in the EoSS data, kop(je), does not appear in the Ameel list. The term tas seems to be similar in dominance to bolli in Icelandic (and tasse in French in the Ameel data) and suggests a broad drinking vessel category, whereas in Netherlands Dutch the same domain is broken down into smaller groups with greater sensitivity to size. We therefore turn in more detail to the extensional patterns in our data.

Table 1

Dominant container terms in two studies. Numbers in brackets indicate the number of different container stimuli for which that term was dominant.

\begin{tabular}{|c|c|c|c|}
\hline $\begin{array}{l}\text { Ameel et al. (2005) } \\
\text { Belgian Dutch monolinguals } \\
\text { ( } 9 \text { head terms) }\end{array}$ & $\begin{array}{l}\text { EoSS: Dutch diminutives collapsed } \\
\text { (10 head terms) }\end{array}$ & $\begin{array}{l}\text { EoSS: Dutch diminutives separate } \\
\text { (12 head terms) }\end{array}$ & $\begin{array}{l}\text { EoSS } \\
\text { Icelandic } \\
\text { (13 head terms) }\end{array}$ \\
\hline $\begin{array}{l}\text { kom (19) } \\
\text { tas }(15) \\
\text { schaal (13) } \\
\text { bord (8) } \\
\text { beker (4) } \\
\text { pot (4) } \\
\text { glas (2) } \\
\text { asbak (1) } \\
\text { houder (1) }\end{array}$ & $\begin{array}{l}\text { schaal (30) } \\
\text { bord (11) } \\
\text { kop (8) } \\
\text { mok (5) } \\
\text { glas (4) } \\
\text { bak (4) } \\
\text { beker (3) } \\
\text { kom (3) } \\
\text { pul (2) } \\
\text { pot (1) }\end{array}$ & $\begin{array}{l}\text { schaal (19) } \\
\text { schaaltje (12) } \\
\text { bord (11) } \\
\text { kopje (8) } \\
\text { bakje (6) } \\
\text { mok (5) } \\
\text { glas (3) } \\
\text { pul (2) } \\
\text { beker (2) } \\
\text { kom (2) } \\
\text { glaasje (1) } \\
\text { potje (1) }\end{array}$ & $\begin{array}{l}\text { skál (29) } \\
\text { bolli (16) } \\
\text { diskur (6) } \\
\text { mót (5) } \\
\text { glas (3) } \\
\text { fat (3) } \\
\text { krús (2) } \\
\text { kertastjaki (1) } \\
\text { mál (1) } \\
\text { krukka (1) } \\
\text { undirskál (1) } \\
\text { kanna (1) } \\
\text { öskubakki (1) }\end{array}$ \\
\hline
\end{tabular}




\subsection{Comparing extensions}

We follow Malt et al. (2003) and Ameel et al. (2005) in comparing extensions by the dominant term (the term most frequently given in response to a particular stimulus). Table 2 lists the dominant terms for each language, ordered to the left by the Icelandic term and to the right by the Dutch term. The stimuli are listed by the number and the English label (description of what is shown in the stimulus picture) that was used by Ameel et al. (2005). When we refer to the extension of a term in this section, we refer to these dominant terms.

For ease of comparison, we also include Table 3 which shows the Icelandic dominant terms listed against the Dutch dominant terms with which they share a stimulus item; the numbers indicate how many stimulus items are shared by the terms. Table 4 shows the Dutch dominant terms listed against the Icelandic ones. Our data elicits two major clusters of terms in each language: one roughly relating to food containers, which we loosely refer to as the bowl-domain; one roughly relating to drink containers, which we loosely refer to as the cup-domain. These are purely terms of convenience to refer to the extensional range of these clusters of terms. It is not intended to imply any privileged status to the English terms cup and bowl nor to the actual divisions that those terms make. As our discussion in Section 4.2 amply demonstrates, languages differ in the placement of specific extensional boundaries and the characteristic properties that influence this boundary placement. Indeed, as our discussion of Dutch kom will show, even the food $\sim$ drink division is not a necessary one.

Consider first the extension of the most frequent dominant term in the Icelandic data: skál. The extension of the Icelandic term is divided between the Dutch terms schaal, schaaltje, bakje, bord and kom. The diminutive term schaaltje is practically a subset of Icelandic skál with the exception of Item 49, which the Icelandic participants primarily perceived as a candleholder but the Dutch participants perceived as a bowl-like item (schaal, schaaltje); both Icelandic skál and öskubakki were codominant terms for the ashtray which in Dutch receives the dominant term schaaltje. The schaaltje items are at the smaller end of the size range for the extension of Icelandic skál. The Dutch term schaal covers the generally larger items (though overlapping with Dutch schaaltje even here in dominant responses) and extends into much larger items that Icelandic lexicalises with separate terms: mót and fat. The Icelandic term mót is generally used for large baking dishes; the Icelandic term fat is generally used for large serving trays or platters.

In addition to Dutch schaal and schaaltje, the extensional space of Icelandic skál is intersected in Dutch by the extensions of bakje, bord, and kom. The extension of Dutch bakje is a subset of the extension of Icelandic skál. It includes small to medium sized round bowl-like items. The Dutch term bak also occurs in our data but never as a dominant term; only one item was named bak by 5 or more participants: a large metal food preparation bowl (Item 50). The Dutch diminutive term bakje is therefore the more frequent and conventionalised in this domain and its extension falls between Dutch schaal and schaaltje. The Dutch term bord cuts across the extension of Icelandic skál, including plate-like and dish-like items referred to in Icelandic as diskur by a majority of respondents, as well as a number of decorative bowls referred to as skál. The extension of Icelandic diskur is a subset of Dutch bord. The term bord is also used for the saucer (Item 3), which is referred to with a separate head term in Icelandic (undirskál). The Dutch term kom occurs for a single item in the extension of Icelandic skál (Item 51, a smallish white bowl, rather low and wide, with black stripes). As Dutch kom also intersects with the extension of Icelandic bolli, which we discuss below, we will deal with it there.

Considering the extension of Icelandic skál, we find evidence for diminutive semantics having an effect on the preferred division within the extensional space. Dutch separates off smaller items under the diminutive term (schaaltje), while grouping

Table 2

Dominant terms for stimuli, sorted by Icelandic (left) and Dutch (right).

\begin{tabular}{|c|c|c|c|c|c|c|c|}
\hline \multicolumn{4}{|c|}{ Dominant terms sorted by Icelandic term } & \multicolumn{4}{|c|}{ Dominant terms sorted by Dutch term } \\
\hline Stimulus \# & Stimulus label & ISL & NLD & Stimulus \# & Stimulus label & NLD & ISL \\
\hline 32 & glass cup with metal handle & bolli & glas & 23 & small brown dish & bakje & skál \\
\hline 37 & glass mug with black handle & bolli & glas & 26 & pink bowl & $\begin{array}{l}\text { bakje, } \\
\text { schaaltje }\end{array}$ & skál \\
\hline 42 & glass mug & bolli & glas & 28 & striped wooden bowl & bakje & skál \\
\hline 14 & white cup with a drawing & bolli & kom & 52 & glass bowl & bakje & skál \\
\hline 1 & white cappuccino cup & bolli & kopje & 53 & square white bowl & bakje & skál \\
\hline 7 & white "café au lait" cup & bolli & kopje & 54 & white plastic bowl & bakje & skál \\
\hline 11 & black cup & bolli & kopje & 30 & green glass & beker & glas \\
\hline 12 & little green cup & bolli & kopje & 25 & white mug with two handles & beker & mál \\
\hline 34 & large white cup & bolli & kopje & 8 & white long dish & bord & diskur \\
\hline 35 & blue cup with green inside & bolli & kopje & 36 & white plate & bord & diskur \\
\hline 44 & light brown cup without handle & bolli & kopje & 41 & plate with green rim & bord & diskur \\
\hline 45 & red cup without handle & bolli & kopje & 47 & green and yellow bowl & bord & $\begin{array}{l}\text { diskur, } \\
\text { skál }\end{array}$ \\
\hline 19 & red “tik-tak" mug & bolli & mok & 62 & black shiny dish & bord & diskur \\
\hline 21 & plain white mug & bolli & mok & 67 & square white serving dish & $\begin{array}{l}\text { bord, } \\
\text { schaal }\end{array}$ & diskur \\
\hline 46 & green mug with face & bolli & mok & 13 & white bowl with a drawing & bord & skál \\
\hline 48 & white mug with drawing & bolli & mok & 15 & white bowl with black rim & bord & skál \\
\hline
\end{tabular}


Table 2 (continued)

\begin{tabular}{|c|c|c|c|c|c|c|c|}
\hline \multicolumn{4}{|c|}{ Dominant terms sorted by Icelandic term } & \multicolumn{4}{|c|}{ Dominant terms sorted by Dutch term } \\
\hline Stimulus \# & Stimulus label & ISL & NLD & Stimulus \# & Stimulus label & NLD & ISL \\
\hline 8 & white long dish & diskur & bord & 18 & plain white bowl & bord & skál \\
\hline 36 & white plate & diskur & bord & 60 & white bowl with roses & bord & skál \\
\hline 41 & plate with green rim & diskur & bord & 3 & white cappuccino saucer & bord & undirskál \\
\hline 47 & green and yellow bowl & $\begin{array}{l}\text { diskur, } \\
\text { skál }\end{array}$ & bord & 16 & wine glass & glaasje & glas \\
\hline 62 & black shiny dish & diskur & bord & 32 & glass cup with metal handle & glas & bolli \\
\hline 67 & square white serving dish & diskur & $\begin{array}{l}\text { bord, } \\
\text { schaal }\end{array}$ & 37 & glass mug with black handle & glas & bolli \\
\hline 57 & oblong white dish with black trim & fat & schaal & 42 & glass mug & glas & bolli \\
\hline 63 & white serving dish & fat & schaal & 14 & white cup with a drawing & kom & bolli \\
\hline 64 & square dish with roses & fat & schaal & 51 & white bowl with black stripes & kom & skál \\
\hline 30 & green glass & glas & beker & 1 & white cappuccino cup & kopje & bolli \\
\hline 16 & wine glass & glas & glaasje & 7 & white "café au lait" cup & kopje & bolli \\
\hline 27 & glass “stella” beer mug & glas, kanna & pul & 11 & black cup & kopje & bolli \\
\hline 49 & glass dish with thick rim & kertastjaki & $\begin{array}{l}\text { schaal, } \\
\text { schaaltje }\end{array}$ & 12 & little green cup & kopje & bolli \\
\hline 6 & painted pot with lid & krukka & potje & 34 & large white cup & kopje & bolli \\
\hline 10 & tall "gouden hoorn" mug & krús & mok & 35 & blue cup with green inside & kopje & bolli \\
\hline 55 & brown "artois" mug & krús & pul & 44 & light brown cup without handle & kopje & bolli \\
\hline 25 & white mug with two handles & mál & beker & 45 & red cup without handle & kopje & bolli \\
\hline 43 & red rectangular dish & mót & schaal & 19 & red "tik-tak" mug & mok & bolli \\
\hline 58 & large square glass bowl & mót & schaal & 21 & plain white mug & mok & bolli \\
\hline 59 & brown dish with small handles & mót & schaal & 46 & green mug with face & mok & bolli \\
\hline 61 & clay pot with handle & mót & schaal & 48 & white mug with drawing & mok & bolli \\
\hline 66 & white ridged bowl & mót & schaal & 10 & tall "gouden hoorn” mug & mok & krús \\
\hline 23 & small brown dish & skál & bakje & 6 & painted pot with lid & potje & krukka \\
\hline 26 & pink bowl & skál & $\begin{array}{l}\text { bakje, } \\
\text { schaaltje }\end{array}$ & 27 & glass “stella” beer mug & pul & glas, kanna \\
\hline 28 & striped wooden bowl & skál & bakje & 55 & brown “artois" mug & pul & krús \\
\hline 52 & glass bowl & skál & bakje & 57 & oblong white dish with black trim & schaal & fat \\
\hline 53 & square white bowl & skál & bakje & 63 & white serving dish & schaal & fat \\
\hline 54 & white plastic bowl & skál & bakje & 64 & square dish with roses & schaal & fat \\
\hline 13 & white bowl with a drawing & skál & bord & 49 & glass dish with thick rim & $\begin{array}{l}\text { schaal, } \\
\text { schaaltje }\end{array}$ & kertastjaki \\
\hline 15 & white bowl with black rim & skál & bord & 43 & red rectangular dish & schaal & mót \\
\hline 18 & plain white bowl & skál & bord & 58 & large square glass bowl & schaal & mót \\
\hline 60 & white bowl with roses & skál & bord & 59 & brown dish with small handles & schaal & mót \\
\hline 51 & white bowl with black stripes & skál & kom & 61 & clay pot with handle & schaal & mót \\
\hline 2 & wooden bowl & skál & $\begin{array}{l}\text { schaal, } \\
\text { schaaltje }\end{array}$ & 66 & white ridged bowl & schaal & mót \\
\hline 4 & glass dish & skál & schaal & 2 & wooden bowl & $\begin{array}{l}\text { schaal, } \\
\text { schaaltje }\end{array}$ & skál \\
\hline 20 & white dish with handles & skál & schaal & 4 & glass dish & schaal & skál \\
\hline 22 & coconut bowl & skál & schaal & 20 & white dish with handles & schaal & skál \\
\hline 29 & metal bowl & skál & schaal & 22 & coconut bowl & schaal & skál \\
\hline 31 & white bowl & skál & schaal & 29 & metal bowl & schaal & skál \\
\hline 38 & earthenware bowl & skál & $\begin{array}{l}\text { schaal, } \\
\text { schaaltje }\end{array}$ & 31 & white bowl & schaal & skál \\
\hline 50 & metal dish & skál & schaal & 38 & earthenware bowl & $\begin{array}{l}\text { schaal, } \\
\text { schaaltje }\end{array}$ & skál \\
\hline 65 & bowl with feet & skál & schaal & 50 & metal dish & schaal & skál \\
\hline 5 & yellow deep bowl & skál & schaaltje & 65 & bowl with feet & schaal & skál \\
\hline 9 & red deep bowl & skál & schaaltje & 5 & yellow deep bowl & schaaltje & skál \\
\hline 17 & yellow dish & skál & schaaltje & 9 & red deep bowl & schaaltje & skál \\
\hline 24 & small white bowl & skál & schaaltje & 17 & yellow dish & schaaltje & skál \\
\hline 33 & black dish & $\begin{array}{l}\text { skál, } \\
\text { öskubakki }\end{array}$ & schaaltje & 24 & small white bowl & schaaltje & skál \\
\hline 39 & black bowl & skál & schaaltje & 33 & black dish & schaaltje & $\begin{array}{l}\text { skál, } \\
\text { öskubakki }\end{array}$ \\
\hline 40 & bowl with chinese pattern rim & skál & schaaltje & 39 & black bowl & schaaltje & skál \\
\hline 56 & small square glass bowl & skál & schaaltje & 40 & bowl with chinese pattern rim & schaaltje & skál \\
\hline 3 & white cappuccino saucer & undirskál & bord & 56 & small square glass bowl & schaaltje & skál \\
\hline
\end{tabular}

together larger items, possibly of a different shape and function, under the non-diminutive form (schaal), whereas Icelandic groups together the small to medium-large items, usually with a round shape, under one broad term (skál) and has specialised terms for large cooking containers (mót) and serving platters (fat). There is also evidence of cross-cutting (Dutch schaal, bord and $\mathrm{kom}$ ) and nesting (Dutch schaaltje and bakje). This suggests that the presence of productive diminutive morphology in the 
Table 3

Icelandic dominant terms listed against Dutch dominant terms.

\begin{tabular}{ll}
\hline Icelandic & Dutch \\
\hline skál & 11 schaaltje, 9 schaal, 6 bakje, 5 bord, 1 kom \\
bolli & 8 kopje, 4 mok, 3 glas, 1 kom \\
diskur & 6 bord, 1 schaal \\
mót & 5 schaal \\
fat & 3 schaal \\
glas & 1 beker, 1 glaasje, 1 pul \\
kertastjaki & 1 schaal, 1 schaaltje \\
krús & 1 mok, 1 pul \\
öskubakki & 1 schaaltje \\
kanna & 1 pul \\
krukka & 1 potje \\
undirskál & 1 bord \\
mál & 1 beker \\
\hline
\end{tabular}

Table 4

Dutch dominant terms listed against Icelandic dominant terms.

\begin{tabular}{ll}
\hline Dutch & Icelandic \\
\hline schaaltje & 11 skál, 1 öskubakki, 1 kertastjaki \\
schaal & 9 skál, 5 mót, 3 fat, 1 diskur, 1 kertastjaki \\
kopje & 8 bolli \\
bord & 6 diskur, 5 skál, 1 undirskál \\
bakje & 6 skál \\
mok & 4 bolli, 1 krús \\
glas & 3 bolli \\
pul & 1 glas, 1 kanna, 1 krús \\
beker & 1 glas, 1 mál \\
kom & 1 bolli, 1 skál \\
glaasje & 1 glas \\
potje & 1 krukka \\
\hline
\end{tabular}

container naming domain has an influence on the placement of extensional boundaries in this domain, interacting with the idiosyncratic language-specific inventory of roots.

Now consider the second most frequent term in the Icelandic data: bolli. Again, this appears to be a rather broad and inclusive category, intersecting with the extensions of Dutch kopje, mok, glas and kom. Although the Dutch term kop occurs in our data, it is never a dominant term (and does not in fact meet our criteria for a high-frequency head term). The extension of Dutch kopje is a subset of Icelandic bolli and it picks out the smaller items, usually with a height no greater than the width, with a single handle or without. The extension of Dutch mok is almost a subset of the extension of Icelandic bolli. It includes items that are generally taller than they are wide, with straight rather than curving sides, a single handle and made of clay or plastic (cf. English mug). The one item in the extension of Dutch mok that does not fall in the extension of Icelandic bolli (Item 10 ) is described as krús in Icelandic. The term krús occurs as a dominant term twice, the other instance being Item 55, which is described in Dutch as pul. The Dutch term pul is used for two large drinking vessels, taller than they are wide with a single handle, one clay, one glass: the clay item is named krús in Icelandic and the glass item is named either glas or kanna in Icelandic. The Dutch pul items would be appropriate for beer and the Dutch mok items for coffee.

In the cup-domain, like the bowl-domain, Icelandic has a broad inclusive term (bolli) which includes small to medium sized items of various shapes, with a number of more specialised terms dealing with larger items (krús and kanna), whereas Dutch has a diminutive term picking out the smaller cup-like items (kopje). In this case, however, the remainder of this extensional space in Dutch is not covered by the non-diminutive form $(k o p)$ but rather by independent lexemes. Icelandic krús and Dutch mok are often treated as translation equivalents (cf. English $\mathrm{mug}$ ), but it is interesting to note that Dutch mok has a wider extensional range as a dominant term than Icelandic krús. This is a natural consequence of Dutch using a diminutive term restricted to the smaller end of the extensional space, whereas Icelandic favours a broad inclusive term (bolli) which is often selected in preference to krús.

As mentioned earlier, Dutch kom includes one item from the extension of Icelandic bolli (Item 14), which is mug-like in having straight sides but cup-like in being slightly wider than it is tall, and one item from the extension of Icelandic skál (Item 51), which is a bowl-like item, rather small and low and much wider than it is tall. The Dutch term kom typically refers to a container for liquid or semi-liquid food, which would usually be eaten with a spoon but may be drunk-'soup' is the major compounding noun, as in soepkom. A kom is typically shallow and wider than it is tall and may or may not have a handle. In Icelandic, the presence of a handle shifts the item to the extension of bolli and its absence together with the wide, low, rounded shape shifts it to skál. The presence or absence of a handle is not decisive for Dutch kom, though its low wide shape and its characteristic function is. 
Finally consider the term glas, which occurs in both Dutch and Icelandic. As mentioned earlier, the Dutch term glas intersects with the extension of Icelandic bolli. Icelandic and Dutch differ in how the material of composition of the container interacts with its typical functions to produce the name glas. ${ }^{6}$ In Icelandic, items that might be used for drinking coffee or tea are given the name bolli, even when they are made of glass, whereas Dutch uses the term glas in each case instead of mok or kopje (Items 32, 37, 42). For each of these stimuli, the item is taller than it is wide, meaning that Dutch mok would be more appropriate than Dutch kopje; however, in our stimulus set, mok is only used for clay and plastic items. Given the non-typicality of these items for both kopje (because of tallness) and mok (because of material of composition), glas is the dominant choice in Dutch. In Icelandic, the tea/coffee-drinking function is overriding. However, glass vessels typically used for consuming other kinds of drinks receive the name glas in Icelandic but not Dutch. Item 27 is a large beer mug made out of glass with a brewery logo on it, named glas in Icelandic; this receives the name pul in Dutch given its function and large size. Item 16 is labelled as a wine glass in the stimulus label. It is unusual as a wine glass in being squat and it is unusual as a bowl in having a stem, and in Icelandic the material of composition determines the naming (glas). In Dutch, the diminutive form is used (glaasje), presumably due to its rather squat shape. Item 30 receives the EoSS label "green glass" but the material might just as easily be a light green plastic. It receives the name beker in Dutch, as does a twohanded mug presumably for children (Item 25). English beaker is also used for brightly coloured, usually plastic, drinking vessels for children. In Icelandic, this container receives the name glas, presumably related to a typical function of cold drink consumption.

Overall, we have to agree with Malt et al. (2003) that a comparison of the extensional space of these languages supports a mix-and-match approach, in that a variety of factors interact to produce the particular pattern of lexicalisation that we find in a language. One important factor, as they suggest, is the availability of productive morphology in the container-naming domain. We claim that diminutive semantics has an influence on the preferred division in the extensional space: this is through separating smaller items from others, rather than larger items from others. However, this claim does not deny that factors relating to form and function are also relevant to differentiation patterns. As we observe, alternative lexicalisations and different prioritisations of semantic features can produce cross-cutting effects in even closely related languages.

With respect to our research questions, we come to the following conclusions: the productivity of the diminutive suffix $-(t) j e$ in the container naming domain in Dutch does have an effect on the placement of extensional boundaries. This effect does not relate to a broad typological difference, as Dutch and Icelandic are both Germanic languages and both have diminutive morphology available in principle. However, only in Dutch is the diminutive highly productive and used in the container domain. As observed earlier, the diminutive does not produce a proliferation of terms in Dutch. Nor does it produce fine-grained nesting of the kind described by Malt et al. (2003) for Spanish. Although schaaltje is nested in the extension of skál, schaal is not and cross-cuts skál, mót and fat. In the cup domain, kopje is nested in the extension of bolli and mok is almost nested as well. But these terms do not represent narrow specialised terms but rather two reasonably broad terms sharing the bulk of the extensional space of bolli. Even in the cup domain, one might say that the diminutive encourages a more even distribution of terms across the space, rather than a proliferation of fine-grained distinctions.

\subsection{A comment on prototypicality}

We saw in the last section that Icelandic has two dominant terms with broad extensions in dominant naming: skál and bolli. Dutch on the other hand favoured diminutives in both these extensional spaces to pick out a size-defined subset, with other lexemes filling in the remaining space. This pattern is also reflected in the patterns of high inter-speaker agreement on naming, which may be taken as evidence of prototypicality of the named item. ${ }^{7}$ Six items received unanimous naming responses in Icelandic for the two head terms skál and bolli.

(4) bolli: Item 1 - white cappuccino cup (21); Item 7 - white "café au lait" cup (21); Item 11 - black cup (21); Item 14 white cup with a drawing (21).

(5) skál: Item 9 - red deep bowl (21); Item 52 - glass bowl (21)

The cup items fit fairly well with the properties identified in práinsson (1979), each having handles and their relative dimensions corresponding to his items 1,2 and 5; EoSS items 1, 7,11 are convex and tapering, though item 14 has straighter sides. However, it is not just relative dimensions that appear to influence this choice, as all four cup items are fairly small. Two of the items also explicitly mention their intended contents - varieties of coffee - and as we will see in a moment, content is a salient feature in classifying containers. The bowl items are rather small and round and might typically be used for preparing or serving food.

\footnotetext{
${ }^{6}$ The Icelandic for the material glass is gler not glas, which is used only for the drinking container.

${ }^{7}$ We sound one note of caution here. As our discussion of the naming of Items 32, 37 and 42 in Dutch as glas rather than mok or kopje shows, a dominant term can win out because the items in question lack a salient property for other terms (here, too tall to be kopje; inappropriate material for mok), so that they represent a kind of fall-back name: glas in Dutch is compatible with a glass vessel for drinking tea or coffee, rather than being prototypical for it. Nevertheless, near-unanimous inter-speaker agreement is a strong index of prototypicality. None of these Dutch items had near-unanimity for glas and in Icelandic, there is close agreement between our results and those of práinsson.
} 
In Dutch, no item receives a unanimous response. There are however six items that receive very high inter-speaker agreement for the dominant head terms beker, bord and schaal.

(6) Item 30: green glass = beker (20), glas (1)

(7) Item 8: white long dish = bord (19), schaal (2)

(8) Item 36: white plate = bord (19), bordje (1), schaal (2)

(9) Item 43: red rectangular dish = schaal (17), schaaltje (2), bakje (2)

(10) Item 63: white serving dish = schaal (17), schaaltje (4)

(11) Item 58: large square glass bowl = schaal (16), schaaltje (5)

Each of the schaal items also receives schaaltje as a response and in the case of two of the three items, this is the reason that schaal is not a unanimous response. What is particularly striking is that in each of these three cases, the item is definitely large and none of them are round. This suggests (cf. our discussion in Section 2.2) that factors other than simple relative size are at play in the semantics of the diminutive here. It also suggests that although the dimunitive form creates a salient division at the smaller end of the extensional space, it is still in some sense derived: the salient exemplar items belong to the nondiminutive category (schaal) and are therefore at the large end of the space, unlike the salient exemplar items for Icelandic skál which are at the smaller end of the scale. Indeed, the three terms with highest inter-speaker agreement in Dutch are all non-diminutives (beker, bord, schaal), even though the related diminutives all occur in our data as head terms.

These differences in inter-speaker agreement emphasise the finding that even closely related speaker communities can differ not only in their category boundaries but also in their salient exemplars. In our study, it is the boundary cases which revealed cross-linguistic convergence, as Icelandic and Dutch agree on the item that is hardest to classify: a painted pot with a lid (Item 6). This received nine head terms in Icelandic and seven in Dutch.

Icelandic: krukka 'jar' (8); skál 'bowl' (4); sykurkar ‘sugar bowl’ (3); krús 'mug' (2); ílát 'container' (2); bolli 'cup' (1); dolla 'pot' (1); hirsla 'chest' (1); ker 'tub' (1)

Dutch: potje 'pot-DIM' (10); pot 'pot' (4); bakje 'container-DIM' (2); doosje 'box-DIM' (2); vaas 'vase' (1); kommetje 'bowl-DIM' (1); schaaltje 'dish-DIM' (1)

Participants were apparently confused by this item, especially with its decorative appearance and lid. The range of responses suggest a number of possible functions for the item. As we will see in the next section, function of item is one critical semantic feature in its classification.

Our analysis points to two important conclusions. First, although the diminutive has an important effect on the placement of extensional boundaries, it is nevertheless not a focus for prototype formation as reflected in high inter-speaker agreement. One might say that diminutive - $(t) j e$ is not just derived in the standard morphological sense but also semantically in that it is the root term not the derived diminutive that provides the prototypical exemplar. Second, the prototypical items in Dutch and Icelandic are quite different, strikingly so in the bowl-domain, where Dutch favours large dishes and Icelandic favours small bowls. This underlines the well-established variation in lexical categories even between closely related languages. This variability is confirmed in the next section, where we will consider some of the salient semantic features that speakers used in compounding and modification to elaborate on the nature of the named object.

\subsection{Semantic features in compounding and modification}

The majority of individual responses in both Icelandic and Dutch were single words naming the object. However, participants often wanted to elaborate their descriptions with greater detail. This was most often achieved by using a compound word that included extra information concerning the stimulus object, e.g. coffee cup, where the typical contents of the stimulus is named as well as the container itself. Sometimes, syntactic modification was used, e.g. a bowl for putting potatoes in, where the information is provided via phrasal periphrasis. And of course, both methods could be used in a single response. In total there were 1407 full responses (21 participants * 67 stimuli). In Icelandic, $31 \%$ of full responses included compounds and $21 \%$ syntactic modification; in Dutch, $12 \%$ of full responses included compounds and $4 \%$ syntactic modification. If one considers only the nominal types (compounds and single nouns), then $83 \%$ of the nominal types were compounds in Icelandic and 66\% were compounds in Dutch.

We classified both the compounds and the syntactic modifiers according to our intuitions concerning the type of semantic information that they added to the head term. These classifications were derived independently by the authors (MW/pGB for Icelandic and FMJ for Dutch) prior to any comparative analysis. We were interested to see whether there was considerable variation even between such closely related languages or whether there were strong candidates for fundamental features of classification which one might predict would occur crosslinguistically. We found one strong candidate for a stable crosslinguistic feature, which chimes well with other findings in the literature: inferred contents of the container. Other than that, there was considerable variation in the kinds of information that was marked, its relative frequency with respect to other marked information and also the way that different kinds of information were marked. Tables 5 and 6 show the results for Icelandic and Dutch respectively. Each semantic feature is listed with the number of full response tokens marking that feature 
Table 5

Summary of Icelandic compounds and modifiers by semantic type.

\begin{tabular}{|c|c|c|c|}
\hline Semantic type (e.g.) & Compound & Modification & Total \\
\hline Contents (coffee) & 230 & 34 & 264 \\
\hline Material (metal) & 126 & 3 & 129 \\
\hline Shape (deep) & 13 & 59 & 72 \\
\hline Attribute (fire-resistant) & 0 & 65 & 65 \\
\hline User (kid) & 37 & 6 & 43 \\
\hline Size (small) & 4 & 33 & 37 \\
\hline Colour (red) & 0 & 33 & 33 \\
\hline Usage (baking) & 25 & 5 & 30 \\
\hline Evaluative (posh) & 0 & 22 & 22 \\
\hline Hedge (could be) & 0 & 17 & 17 \\
\hline Comparison (cup-like) & 5 & 3 & 8 \\
\hline Standard (normal) & 0 & 7 & 7 \\
\hline Origin (Japanese) & 0 & 6 & 6 \\
\hline Placement (under) & 3 & 0 & 3 \\
\hline
\end{tabular}

Table 6

Summary of Dutch compounds and modifiers by semantic type.

\begin{tabular}{|c|c|c|c|}
\hline Semantic type (e.g.) & Compound & Modification & Total \\
\hline Contents (coffee) & 86 & 1 & 87 \\
\hline Usage (baking) & 61 & 2 & 63 \\
\hline Material (metal) & 9 & 22 & 31 \\
\hline Size (small) & 0 & 18 & 18 \\
\hline Shape (deep) & 0 & 14 & 14 \\
\hline User (kid) & 11 & 0 & 11 \\
\hline Colour (red) & 0 & 1 & 1 \\
\hline Comparison (cup-like) & 1 & 0 & 1 \\
\hline Hedge (could be) & 0 & 1 & 1 \\
\hline Placement (under) & 1 & 0 & 1 \\
\hline Attribute (fire-resistant) & 0 & 0 & 0 \\
\hline Evaluative (posh) & 0 & 0 & 0 \\
\hline Origin (Japanese) & 0 & 0 & 0 \\
\hline Standard (normal) & 0 & 0 & 0 \\
\hline
\end{tabular}

by compounding or syntactic modification. The features are ordered by the total frequency, showing how often a particular feature was mentioned by one of the two strategies.

Notice that in both Icelandic and Dutch, by far the most frequently marked information concerns inferred contents of the container and this is marked largely by compounding not modification. After this, there are a number of differences. For instance, material is the second most prominent feature in Icelandic but the third most prominent in Dutch. In Icelandic, material is marked predominantly by compounding but in Dutch predominantly by modification. The second most prominent feature in Dutch is usage, i.e. the action performed with the container (e.g. baking), which is also directly related to characteristic function but comes eighth in Icelandic overall and fourth in compounding. It is difficult to argue from this for a universal palate of semantic features that condition container classification, though inferred contents does appear to be a strong candidate: it is apparently not merely a form of words to say that containers are defined by the things they contain. This fits well with both the Labov and práinsson studies, where contents were seen to have a biasing effect on nonprototypical items. Similar features are also often mentioned in the container literature (cf. Kronenfeld et al., 1985; Malt et al., 2003).

For our purposes, the most important point to note relates to size. There are 588 diminutive tokens in the Dutch data (42\% of full responses). Two points are worth noting. First, despite the extensive use of diminutives, information on size is nevertheless coded by modifiers in Dutch. Indeed one example is heel klein kopje 'a very small cup. DIM'. This suggests that diminutive forms like kopje are partly conventionalised and cannot simply be interpreted as 'small cup', a point emphasised in our initial discussion of the semantic range of diminutives in Dutch. Diminutive objects are readily modified to express (yet) smaller size, without tautology.

The second point is that there is a real difference with Icelandic here. There are 4 tokens of size compounding ${ }^{8}$ in Icelandic (out of 431 compounding tokens in all) and 33 tokens of size modification (out of 293 in all). That is 37 tokens marking size information, compared with the 588 diminutives and 18 modifiers in Dutch. Further, even if one ignores dimunitives, size is the fourth most common feature marked in Dutch by either compounding or modification, whereas size is the sixth most common feature in Icelandic.

\footnotetext{
${ }^{8}$ smá- 'small' (2), mini- 'mini' (1), ör- 'tiny' (1).
} 
Overall, the compounding and modification data confirms the importance of inferred contents to container classification and shows a strong tendency in both languages to mark this feature by compounding. Other than this, however, there is considerable variation in the type and prominence of semantic features which are marked by participants as well as in the preferred strategies for marking these features. However, the difference with respect to diminutives is not merely a difference in strategy: Icelandic does not mark size-related information as extensively by compounding or modification as Dutch does by diminutives. Rather, the diminutive in Dutch gives a prominence to size-related information that we do not see in Icelandic.

\section{Conclusion}

An analysis of the extension of dominant terms for containers in Dutch and Icelandic suggests that productive morphology in the naming domain can have an influence on boundary placement within the extensional space, as suggested by Malt et al. (2003): the Dutch diminutive -(t)je picks out the smaller items in a domain, leaving the non-diminutive or other lexical items to fill the remaining space. In Icelandic, wide coverage terms are used for the small to medium-large items, with narrow terms carving up the larger items. This effect does not relate to a broad typological difference, because Dutch and Icelandic are both Germanic languages and both have diminutive morphology available in principle. Rather it is simply a reflex of the particular morphemes that are productive within the relevant domain. Unlike Malt et al. (2003), we find no evidence of such morphemes producing a proliferation of terms and fine-grained nesting within the extensional domain, even though about a third of the high-frequency head terms are diminutives. Rather, the use of the diminutive favours the differentiation of a set of "smaller" items with a sharing out of the remaining space by other lexemes. Icelandic has two very wide coverage terms; Dutch has a more even spread across the extensional space.

Despite this influence on the placement of extensional boundaries, diminutive formation does not produce an independent prototypical exemplar reflected in inter-speaker agreement. On the contrary, it is the non-diminutive term schaal that produces the clearest inter-speaker agreement, not schaaltje. All three high-agreement terms in Dutch (beker, bord, schaal) are non-diminutives. The fact that diminutive schaaltje is also a marginal response for the large items with high inter-speaker agreement for schaal suggests other aspects of the sense network of diminutives is also at work here, for instance the 'attitudinal' use of the diminutive (Shetter and Ham, 2007), conveying some evaluative stance on the part of individual speakers with respect to an item or their classification of it.

Our analysis of compounding and modification points to a number of semantic features which speakers use when attempting to differentiate an item, such as typical contents, material of composition, shape, intended usage and intended user. By far the most common feature in both languages is the typical content(s) and this appears to play a crucial role in defining the characteristic function of the container (a container is defined by what it contains). Beyond this commonality, we see variation in the range of semantic features profiled in the two languages and sharp differences in the frequency with which particular features occur.

Considering the extensional space as a whole, we agree with Malt et al. (2003) that a mix-and-match approach is necessary in considering the data, with extensional divisions in particular languages reflecting a complex interplay of different factors, including linguistic, cultural and cognitive factors. Linguistic factors include not only the lexical stock that happens to be available in a language and their conventions of use but also the availability of productive morphology within the domain in question. Our results demonstrate that in order to understand the processes that produce semantic divisions of basic object classes, we should consider fine-grained analyses of closely related languages alongside analyses of typologically different languages.

\section{References}

Ameel, E., Storms, G., Malt, B.C., Sloman, S.A., 2005. How bilinguals solve the naming problem. J. Mem. Lang. 53, 60-80.

Berlin, B., 1992. Ethnobiological Classification: Principles of Categorization of Plants and Animals in Traditional Societies. Princeton University Press, Princeton, N.J.

Booij, G.E., van Santen, A., 1998. Morfologie. Amsterdam University Press, Amsterdam.

Boroditsky, L., 2006. Linguistic relativity. In: Encyclopedia of Cognitive Science. John Wiley \& Sons, Ltd.

Brachin, P., 1985. The Dutch Language: a Survey. Brill, Leiden.

Chomsky, N., 2003. Reply to Horwich. In: Antony, L.M., Hornstein, N. (Eds.), Chomsky and His Critics. Blackwell, Oxford, Malden, MA, pp. 295-304.

Cohen, A., 1958. Het Nederlandse diminutiefsuffix: een morfonologische proeve 51, 40-45.

Donaldson, B., 2003. Dutch: a Comprehensive Grammar. Routledge.

Fodor, J.A., 1975. The Language of Thought. Crowell, New York.

Hunn, E.S., 1977. Tzelta Folk Zoology: the Classification of Discontinuities in Nature. Academic Press, New York.

Jóhannesson, A., 1927. Die Suffixe im Isländischen. Gutenberg, Reykjavík.

Jónsson, J.H., 1988. Hefð og hneigð í íslenskri orðmyndun. Málfregnir 2 (1), 3-11.

Jurafsky, D., 1996. Universal tendencies in the semantics of the diminutive. Language 72, 533-578. http://dx.doi.org/10.2307/416278.

Kronenfeld, D.B., Armstrong, J.D., Wilmoth, S., 1985. Exploring the internal structure of linguistic categories: an extensionist semantic view. In: Dougherty, J.

W.D. (Ed.), Directions in Cognitive Anthropology. University of Illinois Press, Urbana, pp. 91-113.

Kvaran, G., 2005. Íslensk tunga II: Orð. Almenna bókafélagið, Reykjavík.

Labov, W., 1973. The boundaries of words and their meanings. In: Bailey, C.-J.N., Shuy, R.W. (Eds.), New Ways of Analyzing Variation in English. Georgetown University Press, Washington, pp. 340-373.

Lucy, J.A., 1992. Language Diversity and Thought: a Reformulation of the Linguistic Relativity Hypothesis. Cambridge University Press, Cambridge.

Majid, A., Jordan, F., Dunn, M., 2011. Evolution of Semantic Systems Procedures Manual. Max Planck Institute for Psycholinguistics, Nijmegen.

Malt, B.C., Majid, A., 2013. How thought is mapped into words. Wiley Interdiscip. Rev. Cogn. Sci. 4, 583-597. http://dx.doi.org/10.1002/wcs.1251. 
Malt, B.C., Sloman, S.A., Gennari, S., Shi, M., Wang, Y., 1999. Knowing versus naming: similarity and the linguistic categorization of artifacts. J. Mem. Lang. 40, 230-262. http://dx.doi.org/10.1006/jmla.1998.2593.

Malt, B.C., Sloman, S.A., Gennari, S.P., 2003. Universality and language specificity in object naming. J. Mem. Lang. 49, 20-42. http://dx.doi.org/10.1016/S0749596X(03)00021-4.

Rosch, E., 1973. On the internal structure of perceptual and semantic categories. In: Moore, T.E. (Ed.), Cognitive Development and the Acquisition of Language. Academic Press, New York, pp. 111-144.

Rosch, E., 1975. Cognitive representations of semantic categories. J. Exp. Psychol. Gen. 104, 192-233.

Sapir, E., 1912. Language and environment. Am. Anthropol. 14, 226-242. http://dx.doi.org/10.1525/aa.1912.14.2.02a00020.

Sapir, E., 1929. The status of linguistics as a science. Language 5, 207-214. http://dx.doi.org/10.2307/409588.

Shetter, W.Z., 1959. The dutch diminutive. J. Engl. Ger. Philol. 58, 75-90.

Shetter, W.Z., Ham, E., 2007. An Essential Grammar. Routledge, London.

práinsson, H., 1979. Hvað merkir orðið bolli? (What does the word cup mean?) Íslenskt Mál 1, 96-106.

Van der Hulst, H., 2008. The dutch diminutive. Lingua Trends Prosodic Phonol. 118, 1288-1306. http://dx.doi.org/10.1016/j.lingua.2007.09.012.

Vikør, Lars S., 2001. The Nordic Languages. Their Status and Interrelations. Nordic Language Council \& Novus Press, Oslo.

Whorf, B.L., 1956. Science and linguistics. In: Chase, S., Carroll, J.B. (Eds.), Language, Thought, and Reality: Selected Writings of Benjamin Lee Whorf. MIT Press, New York, pp. 207-219. 